\title{
UNDERSTANDING THE DYNAMIC BEHAVIOUR OF THE AUSTRALIAN RETIREMENT VILLAGE INDUSTRY: A CAUSAL LOOP DIAGRAM
}

\author{
Bo XIA (1D ${ }^{1,}{ }^{*}$, Qing $\mathrm{CHEN}^{1}$, Jerry WALLIAH ${ }^{1,2}$, Laurie BUYS (D) ${ }^{3}$, Martin SKITMORE (D) ${ }^{1}$, \\ Connie SUSILAWATI ID 4
}

\author{
${ }^{1}$ School of Architecture and Built Environment, Queensland University of Technology, Brisbane, Australia \\ ${ }^{2}$ Department of Architecture and Construction Management, Papua New Guinea University of Technology, Lae, Papua New Guinea \\ ${ }^{3}$ Faculty of Health and Behavioural Sciences, University of Queensland, Brisbane, Australia \\ ${ }^{4}$ School of Economics and Finance, Queensland University of Technology, Brisbane, Australia
}

Received 04 February 2021; accepted 07 May 2021

\begin{abstract}
The retirement village industry in Australia has been accommodating an increasing number of residents in recent decades. However, a thorough understanding of the dynamic behaviour of the industry remains largely unknown, which prevents a better prediction of its future growth. This study incorporates system dynamics thinking into residents' relocation decisions and aims to develop a causal loop diagram to have a full understanding of the complex interactions of variables affecting their relocation, which in turn determines the future growth pattern of the industry. Based on thematic analysis using literature review and interview data, five primary causal loops are identified, including the positive reinforcing loops of word-of-mouth effect and new-supply effect, and three negative balancing loops of the move-out effect, price effect and home-village distance effect. Of these five causal loops, the most dominant ones in determining the system behaviour are the word-of-mouth (reinforcing) and home-village distance (balancing) effects. The causal loop diagram provides a better understanding of the underlying structure of the retirement village industry and will help guide the industry and policy makers in formulating strategies to create a more ageing-friendly living environment for seniors in Australia.
\end{abstract}

Keywords: retirement villages, older people, systems thinking, system behaviour, causal loop diagram, Australia.

\section{Introduction}

The ageing population in Australia is steadily increasing, with the proportion of people at least 65 years old expected to increase to around $25 \%$ by 2056 (Australian Bureau of Statistics [ABS], 2012). This poses a significant challenge to understanding how to provide appropriate accommodation and care for older people, who need not only a secure and comfortable living environment, but also social environments that meet their expectations and support their ongoing engagement within the community (Cotter et al., 2012). In particular, the baby boomers - those born between 1946 and 1964 - have a higher expectation of housing, neighborhood qualities, facilities, services, travel and recreation (Wright et al., 2014). The increasing demand for housing of the older population will put severe pressure on the current and future housing industry.

Retirement villages (RVs) are one type of accommodation that provides age-specific housing for older people. The term "retirement village" in the Australian context normally refers to a community or a complex containing residential premises that are occupied predominantly or exclusively by retired persons (Buys et al., 2006; Parliament of Australia, 2007). It is usually a gated and agesegregated community (for people at least 55 years old) with a range of facilities and services to support residents' living in their later life (Bernard et al., 2007; Sim et al., 2011). The average age of residents moving in is around 75 , and they normally stay for $8-9$ years (PwC, 2019). There were over $2300 \mathrm{RVs}$ for more than 184000 seniors in 2014 in Australia - approximately 5.2\% of people aged 65+ (Property Council of Australia, 2014).

Despite the increasing number of people relocating into RVs in recent years, the future growth of the Australian RV industry remains unclear. On the one hand, the industry is perceived by the government and society as delivering a critical element of housing options for older Australians. The industry projection is that around 7.5\% of people $65+$ will be residents by 2025 (Property Council of Australia, 2014). On the other hand, the 5.57 million

${ }^{*}$ Corresponding author. E-mail: paul.xia@qut.edu.au

Copyright $\odot 2021$ The Author(s). Published by Vilnius Gediminas Technical University

This is an Open Access article distributed under the terms of the Creative Commons Attribution License (https://creativecommons.org/licenses/by/4.0/), which permits unrestricted use, distribution, and reproduction in any medium, provided the original author and source are credited. 
Australian baby boomers are largely rejecting RVs in recent years and occupancy rates have also been dropping steadily in recent years: from $93 \%$ in 2017 to $89 \%$ in 2019 (PwC, 2019). RVs are commonly perceived as places for "old people" and are viewed by most of baby boomers as being places for those "fragile" enough to be in need of care. It is widely recognized that the vast majority of baby boomers wish to age-in-place, i.e., living at home in the community as long they can.

In order to understand and predict the future growth of the Australian RV industry better, a thorough understanding of industry behavior is needed. However, this is not an easy task. The industry is a dynamic and complex system, consisting of multiple interdependent stakeholders such as developers, potential and current residents and private and not-for-profit service providers. In addition, a variety of factors affect the potential residents' decision to relocate to, or current residents' decision to leave, RVs, including affordability, proximity to the previous home, village services and amenities and services available in the local area. Although a number of studies in recent decades have shed light on how these factors influence the relocation decision-making of potential residents (e.g. Buys, 2001; Stimson \& McCrea, 2004), there has been no systematic evaluation of their interactions/interdependence. In addition, the studies do not take into account how the relationships change over time. As a result, the dynamic behaviour of the industry (such as exponential growth or decline, or oscillations) remains largely unknown.

Therefore, systems thinking - defined by Arnold and Wade (2015) as a systemized "set of synergistic analytic skills used to improve the capability of identifying and understanding systems, predicting their behaviors, and devising modifications to them in order to produce desired effects" - is urgently needed to grasp a bigger picture of industry behavior. Accordingly, this study presents a causal loop diagram (CLD) to reveal the system structure of the Australia RV industry, including the interrelationships between the causal factors that affect potential and current residents' relocation decision-making. The CLD is a powerful tool in the system thinking field, which enables the feedback structure between these causal factors to be portrayed (Agnew et al., 2018). It is expected that a better understanding of the dynamic behavior of the industry will help guide the industry and policy makers in formulating strategies for creating a more ageing-friendly living environment for seniors in Australia.

\section{Retirement villages in Australia: "like it or hate it"}

Unlike aged care facilities or nursing homes, which accommodate those in need of intensive care, Australian RVs are occupied primarily by independent-living older people (Parliament of Australia, 2007). As an age-oriented living environment, the built environment, community facilities, services and activities should cater to the unique requirements of such adults (Nathan et al., 2014).
The potential residents make their choice to relocate to RVs based on various factors, such as declining health, house-related needs, the insecurity and social isolation of living in their own homes and neighborhood and death of a spouse or close friend (e.g. Buys, 2001; Crisp et al., 2013). In particular, maintaining social networking is one of the attractions for potential residents (Buys, 2001; Adams et al., 2004) because they normally provide various social and leisure activities (Grant, 2007). A study by Xia et al. (2014) reported that $46 \%$ of residents always attend social group activities, with another $42 \%$ usually attending. In addition, RVs can provide a positive built and social environment with various services, amenities, wider neighborhood and a suitable pedestrian infrastructure. All these have positive effects on the residents' active living (Nathan et al., 2014).

Although RVs play an important role in accommodating senior Australians, the general public and their residents have mixed, sometimes even quite extreme, views on this housing option. For those that favour RV living, the RV community offers care service amenities that particularly facilitate the needs of potential residents. In addition, RV communities enable people to intensify their peer interaction and develop their interests in common. Buys and Miller (2007), for instance, observe that RV residents report a greater participation in leisure, social and physical activities than their community-dwelling peers. Similarly, according to Gardner et al. (2005), dwellers often feel improved life quality, a harmonious environment, assisted living and security and other benefits after moving into RVs; while Seifert and Schelling's (2018) longitudinal survey reveals that residents' perspectives of RVs alter positively after entry. Given the anticipated increase in retirees, the optimistic estimation is that the demand for RV living will boom over the next decades.

Meanwhile, for many residents, the RV living environment is quite restrictive, as they need to follow social norms and regulations, which may restrict their freedom and choice (Faulkner, 2001). Thus, for some potential residents, the prospect of relocating into RVs implies the loss of privacy and autonomy. In addition, that most village residents are older people living in normally gated communities can promote an image of age ghettoism and ageconscious identities (Bohle et al., 2014; Gracia et al., 2010). Furthermore, when people relocate into RVs, they usually lose their social connection with their original living communities, and it takes time and effort to make new friends and establish new social networks, which may create stress for new residents and sometimes even lead to social isolation, especially for male residents. Finally, the affordability of RV living, especially in for-profit RVs, has long been an issue for the vast majority of potential residents, as they normally experience a reduced financial capability after their retirement (Walker \& McNamara, 2013).

As a result, RV living is not the first choice for most Australians (Omoto \& Aldrich, 2006), resulting in Australia having a comparatively lower proportion of people living in RVs than such other countries as the United 
States and New Zealand. It is also observed that many RVs are serious business ventures, established with the sole purpose of profiting from turnover (Xia et al., 2015; Zuo et al., 2014). Therefore, the future growth of the Australian RV industry remains unclear.

\section{Research methodology}

As an exploratory research to understand the dynamic behavior of the Australian retirement village industry, this study adopted the systems thinking approach for the research purpose. According to Forrest (2008), systems thinking can effectively portray a system's nonlinear behavior and structure over time by establishing interactions and feedback between variables through the modelling process, which includes the development of a qualitative conceptual model and final quantitative simulation. As a part of an ongoing research project, the current research focuses on developing a qualitative conceptual model using causal loop diagrams (CLDs) to understand the system behavior of the Australian RV industry.

As an effective qualitative tool in system thinking, the causal loop diagram (CLD) is to reveal the causal relationships between various factors from a systems viewpoint and provides a powerful tool to uncover such underlying feedback structures and provide a language for presenting the dynamic and interconnected nature of a complex system (Kwoun et al., 2013; Agnew et al., 2018). CLDs are portrayed by variables and arrows (i.e. causal links that connect these variables) to show the cause and effect relationship involved. The arrows can be positive (+) or negative $(-)$, where a positive arrow from one variable (the cause) to the next (the effect) means that the change in the cause and effect is in the same direction, while a negative arrow means that the cause and effect move in the opposite direction. When these causal links start and end at the same variable, they form a feedback loop, which can be either reinforcing (R) or balancing (B): a R loop indicates a continuously increasing or decreasing action in the system, while a B loop attempts to reduce changes and produce stability in the system.

The development of a typical CLD includes two steps, namely the problem articulation or conceptualization and the formulation of dynamic hypothesis (Sterman, 2001). In the first step of problem articulation, research problems and key variables or concepts are identified through common methods such as literature review, interviews, and action research. In the second step of formulating dynamic hypotheses, endogenous and exogenous variables will be identified to understand the system boundary and primary components of the system, and it will then lead to the development of CLDs to reveal the system structures.

The overall process of developing the CLDs in this study is as follows: first, a comprehensive literature review and content analysis (covering both academic publications and industry reports) was conducted to identify underlying variables affecting older people's relocation decision into RVs and major features of the industry (e.g. popula- tion of RV residents, average RV study, RV stock, etc.). After that, 10 interviews with village managers from $10 \mathrm{RVs}$ were conducted so as to identify any new variables and causal loops that may affect the system behavior. After the data collection, the data analysis procedure was following Kim and Andersen (2012), which draw on grounded theory developed in sociology to identify problems, key variables (including endogenous and exogenous ones), and their structural relationships by systematically coding purposive texts for a systems thinking. The grounded theory, with the primary goal of theory generation rather theory testing, generates a theory inductively from raw qualitative data (Charmaz, 2006), the process of which resembles the developmental steps of casual loop diagrams to reveal the system behavior. Eventually, a causal loop diagram of the Australian retirement village industry was developed, consisting of 6 major causal loops, including three reinforcing (R) and three balancing (B) loops. The overall research process in shown in Figure 1. The detailed process of data collection and data analysis is presented in the section below.

\section{Research methods and process}

\subsection{Data collection}

The primary data collection methods used to develop the CLD start with a comprehensive review of such secondary data as industry reports and academic literature to understand the reasons why people decide whether or not to move into RVs, and to have a holistic picture of the Australian RV industry: such as the resident population, RV numbers and their change over time.

Following $\mathrm{Hu}$ et al. (2017), the secondary data were collected from various sources including influential research databases (comprising Google Scholar, Scopus and Web of Science for academic journal articles and conference proceedings), public websites of Australian government departments and various national organizations and institutions (such as The Retirement Living CouncilProperty Council of Australia, Australian Housing and Urban Research Institute), websites of major Australian

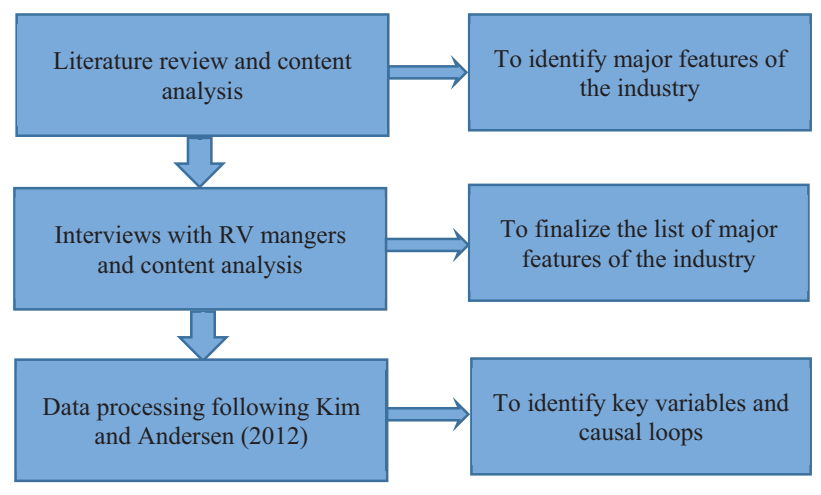

Figure 1. Research process for the development of the causal loop diagram 
retirement village developers and professional services providers (such as Grant Thornton and PwC Australia). The keywords used in the data collection include "retirement village(s)" and other similar terms used interchangeably to present retirement villages in Australia, including "independent living unit(s)/villas", "serviced unit(s)/ apartment(s)", "lifestyle village(s)", "residential park", "self-care unit(s)", "independent living village(s)" and "retirement community/communities". The research period was not restricted because the retirement village is a post1950s phenomenon in Australia.

Interviews were subsequently carried out to identify any new variables and interactions not found in the literature review. In addition, the interview method is also suited for the development of causal loops because it can provide an explanatory description of the system's behavior (Yearworth \& White, 2013). Moreover, the interviews also serve the purpose of validating the primary findings (e.g. the variables and their interactions) identified from the literature review.

A total of 10 semi-structured interviews with village managers from $10 \mathrm{RVs}$ were conducted. As the aim of the research was to develop a conceptual model on the industry level, the target respondents shall be retirement village mangers who have the business management experience and village operation expertise, thus, the residents (and their families) were not involved in the data collection. Being retirement village mangers, all the interviewees have sufficient working experience and knowledge of the business operations related to the Australian RV industry. Furthermore, the data saturation has been achieved in the interview process because no new variables or casual loops were obtained after the 8th interviews, and then confirmed with following two interviews.

As the ultimate purpose of the research is to reveal the future growth of the industry mainly in terms of the likely number of residents involved, the interview questions focused on how individual RVs attract potential residents, retain existing residents and what affected their decision to invest in the RV business. Other useful documentation in each village (e.g. brochure, site map and official website information) was also collected to obtain a more thorough understanding of RV profiles, especially their geographical location, and distance to the CBD and surrounding communities and amenities.

\subsection{Data analysis}

The data analysis procedure follows Kim and Andersen (2012) in systematically coding qualitative data to identify problems, key variables and their structural relationships for systems thinking. Thus, it can generate new knowledge inductively from raw qualitative data (Charmaz, 2006), the process of which resembles the developmental steps of casual loop diagrams to reveal the system's behavior.

The first step involves thematic content analysis and the open coding of data for examining ideas and meaning in the text, and identifying key variables and their causal relationships (Kim \& Andersen, 2012). During the open coding process, the data related to reasons affecting potential residents and current residents' relocation behavior are first broken down into smaller units, such as words, phrases, sentences and paragraphs, to discover the intrinsic themes involved. These segments are closely examined for similarities and differences, and each phenomenon is labelled. Open coding is used to define the problem, set the system boundary, identify the key variables involved (i.e. those influencing the population growth of residents in the RV industry and those present the key features of the industry) and examine the causal and interactive relationships between variables. In particular, the key variables affecting the potential and current retirement village residents' relocation behavior were analyzed thoroughly. The second step of axial coding usually follows open coding, during which, the deconstructed data are reassembled by finding relationships between the code categories - defining the relationships between categories is an important step of conceptualization that can lead to discovery of a theory. A step similar to axial coding is used here to merge key variables affecting the population growth in retirement villages and identify their causal relationships to generate a CLD. This was built using Vensim PLE: a software package designed for developing and analysing dynamic feedback models.

It should be also borne in mind that, as the focal point of CLD analysis is to reveal the dynamic behavior of the RV industry, only the most essential variables/elements of the system are identified at this stage, and variables that do not bring behavior change are not to be considered. For example, many people move into RVs due to health concerns when they reach a certain age; however, given that this only leads to a comparatively stable proportion of people moving into RVs, it will not cause the structural behavior of the system to change. Thus, such variables are not included in the CLD development.

\section{Development of the RV industry CLD}

\subsection{Purpose of the model}

According to Albin et al. (2001), a model's purpose is usually to (1) clarify knowledge and understanding of the system, (2) discover policies that will improve the system's behavior and (3) capture mental models and serve as a communication and unifying medium.

Although the current RV industry is experiencing an increasing number of people moving into RVs, the proportion of the total $65+$ age population is relatively small compared to such other countries as New Zealand, the United States and the United Kingdom - making current existing predictions of the future population of RVs seem overly optimistic. Therefore, the purpose of the model is to understand the future growth of the population of Australian RV residents in the medium to long-term. 


\subsection{System boundary and subsystem diagram}

Every feedback system has a closed boundary containing all necessary (endogenous and exogenous) components (Albin et al., 2001). In the RV system, the interactions between current residents, new move-in residents, potential residents contacted by current residents, move-out residents and RVs are the primary causal components of its dynamic behavior. Table 1 shows the primary components/ variables of the RV system based on the data analysis of the comprehensive literature review and interviews with RV managers. These components cover both (1) key variables affecting both current and potential residents' relocation behavior such as price, distance to original homes, retirement village acceptance, and current residents' contact with potential ones, and (2) key features of the industry that interconnected and have causal relationships with those key variables, such as resident's population, retirement village stock and vacancy rate, and contact rates of residents. These variables can be also divided into endogenous and exogenous variables, with former ones affected by the variables within the system and latter ones are external variables (input) affect but not affected by the system.
The subsystem diagram (Figure 2) demonstrates the high-level causal dynamics at play between these components. As the purpose of the CLD is to reveal the dynamic structure of the retirement village industry (the system) and understand the future growth of the population of Australian RV residents living in retirement villages in the medium to long-term, the sub-systems in this research thus include primarily the residents and the retirement villages. The sub-system of RV residents include those potential residents, new move-in residents, current residents, and those move-out from existing retirement villages. The retirement village sub-system is mainly featured by the stock/capacity, price, vacancy rate, and location (home-village distance), which affect residents' relocation decision making. Figure 1 shows how potential residents, through contact with current residents, become new residents that impact on the current residents and existing RVs. This will change the industry dynamics (e.g. new construction, price change, longer distance to original communities, etc.) that, in turn, impact on potential and new residents.

Table 1. Components of the RV industry system

\begin{tabular}{|c|c|}
\hline Endogenous component/variable & Exogenous component/variable \\
\hline RV residents (population) & Contact rate of residents \\
\hline New move-in RV residents & Average stay period in RVs \\
\hline Move-out RV residents & RV acceptance of potential residents \\
\hline \multicolumn{2}{|l|}{ RV residents' contacts with potential residents } \\
\hline \multicolumn{2}{|l|}{ RV stock } \\
\hline \multicolumn{2}{|l|}{ New RV } \\
\hline $\begin{array}{l}\text { RV features } \\
\text { - Vacancy rate } \\
\text { - Price } \\
\text { - Distance to original homes (home-village distance) }\end{array}$ & \\
\hline
\end{tabular}

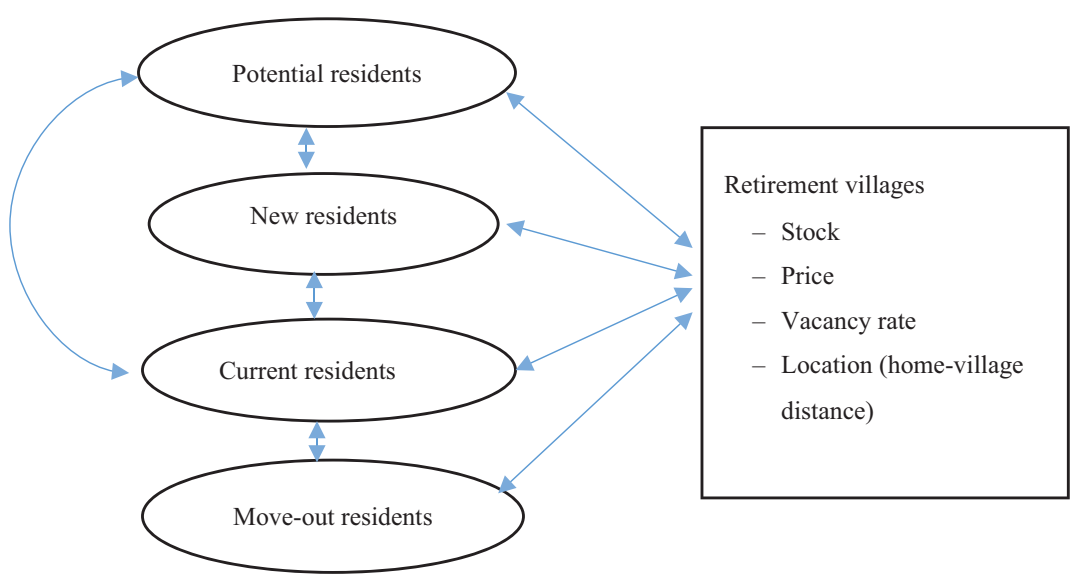

Figure 2. Subsystem diagram of the RV industry 


\subsection{Casual loop diagram}

Figure 3 presents the final CLD, consisting of 6 major causal loops, including three reinforcing $(\mathrm{R})$ and three balancing (B) loops. The reinforcing loops lead to the exponential growth of the resident population, while the balancing loops reduce growth and lead to system stability. Details of the individual causal loops are explained below.

\subsubsection{Reinforcing causal loop 1 (R1) - the word-of- mouth effect to attract new residents}

The word-of-mouth loop is a virtuous cycle that increases the population of residents in RVs, which leads to more contacts or visits with potential residents (normally their neighbours, friends with similar age) if the contact rate (i.e. number of people each resident contact every year) remains constant. The increase in contacts with potential residents then leads to an increase of new residents moving-in if the conversion rate (proportion of contacted potential residents becoming new residents) remains constant, which again increases the proportion of current residents. Word-of-mouth is a strong reinforcing loop and, for potential residents, a positive visit experience has a much more important influence than traditional advertising (Stimson \& McCrea, 2004).

Based on the interviews with RV managers and the literature (e.g. Stimson \& McCrea, 2004), most residents are from local neighborhoods. The majority of residents make their relocation decisions as a result of prior visits to RVs (with positive experience) or to follow their neighbors or friends from their regional communities now living there, i.e., to maintain their original social networks. Therefore, the word-of-mouth effect, i.e., positive feedback or influence from existing residents, plays an essential role in attracting potential residents.
4.3.2. Reinforcing causal loop 2 (R2) - the new supply effect to accommodate more residents

The increase of residents leads to an increase of occupancy rate or drop in vacancy rate. With the drop of the vacancy rate, especially when the spare RV capacity cannot accommodate the new demands from potential residents, new RVs are accordingly developed, although the new supply tends to be delayed because of the construction time required. When the supply increases, the sale/rent price drops accordingly if other factors remain unchanged; thus, the conversion rate increases because the RV option becomes more attractive to potential residents - leading to more new residents.

Although the decision-making of individual developers of new RVs is much more complicated in practice, their investment and development at the industry level is largely driven by demand and supply. For investors, the vacancy/occupancy rate normally serves as an important economic indicator of the RV industry's overall health, and help them determine whether to build new villages or enter into a new market.

\subsubsection{Negative causal loop 1 (B1) - the move-out effect of existing residents}

Residents normally move-out when they are no longer able to live independently or upon death. Thus, the annual number of departing residents is mainly determined by the average length of time people stay. According to the recent national retirement census by $\mathrm{PwC}$ (2019), the average time of residence is $8-9$ years. Although there are several reasons why residents leave their village (e.g. unsatisfactory village services, increased on-going costs and social isolation), the move-out effect on the industry level is mainly due to the physical challenges of residents to retain their

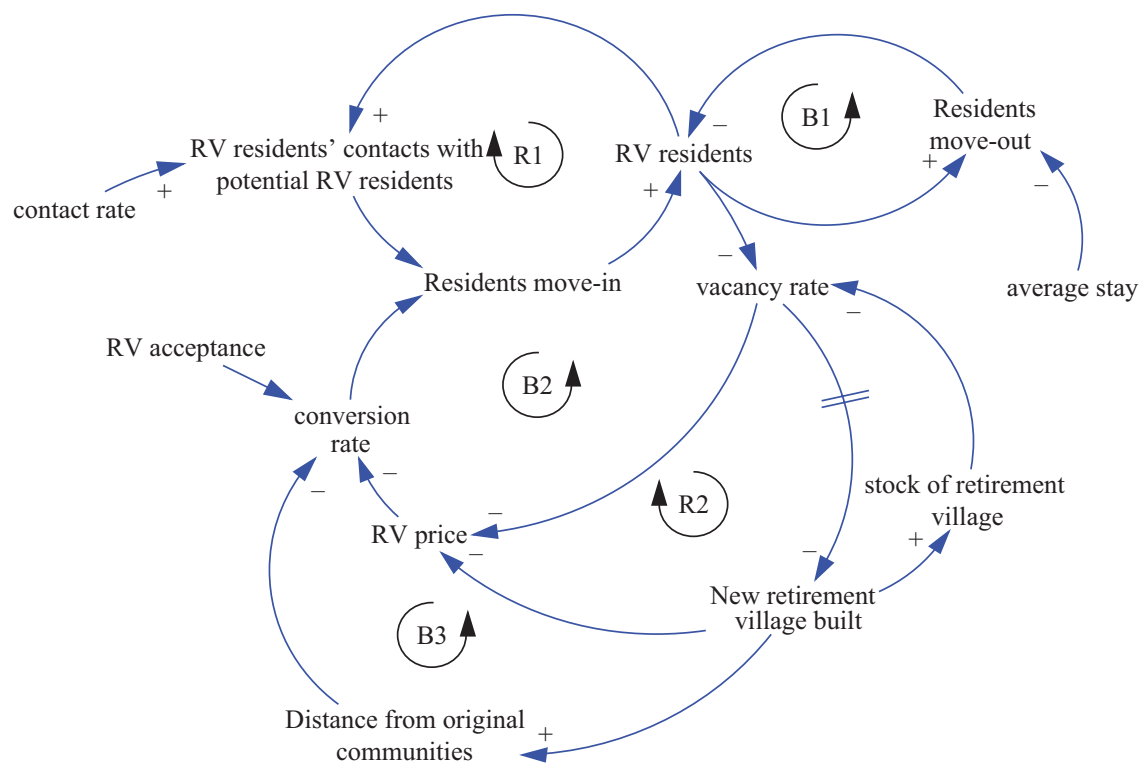

Figure 3. Causal loop analysis of the future growth of the Australian RV industry 
independence. To better serve this cohort, around 30\% of the surveyed RVs in the PwC (2019) census reported having co-located or closely proximate aged care facilities.

\subsubsection{Negative causal loop 2 (B2) - the affordability effect}

It is widely accepted that providing affordable RV living for the full socioeconomic spectrum of retirees is always a major challenge for the industry, especially given that current private providers are mainly profit-driven (Zuo et al., 2014). In early days, RVs were primarily provided by not-for-profit organizations (such as churches and charity organizations) with a lower price for those with low income or no family support. Currently, private RVs (or residents-funded ones) dominate the market, with the national average two bedroom individual-living-unit price being $64 \%$ of the comparable median house price in the same postcode ( $\mathrm{PwC}, 2019)$. Though the cost of moving in is comparatively low, residents when moving out need to pay around $30 \%$ of sale price to the operator as a deferred management fee, which renders the comparatively lower entry cost less attractive or affordable.

The specific balancing causal loop of the affordability-effect works as follows. First, the increase in resident population leads to a lower vacancy rate (or higher occupation rate). Then, before the investment in and construction of new RVs, the developers increase the sale price on the market, which results in a lower conversion rate due to affordability issues when other factors remain unchanged - thus, balancing the exponential growth of new move-in residents.

\subsubsection{Negative causal loop 3 (B3) - the distance-from- the-original community effect}

Compared with the word-of-mouth effect that attracts potential residents, the distance of RVs from original communities/homes is the most important counterpart factor preventing their relocation. As one of the RV managers mentioned, most residents choose RVs less than $30 \mathrm{~km}$ from their original homes: about half an hour driving distance. This corresponds with findings from prior studies, in that almost 66\% of residents move less than $20 \mathrm{~km}$ (Stimson \& McCrea, 2004). Although a new RV located further away may be obtainable at a lower price (or better affordability), it can also involve the loss of social connections with neighbors, friends and family members. For many potential residents, establishing a new social network in a completely new environment poses significant challenges and can even lead to social isolation. This also corresponds with the observations from case RVs that most residents are from nearby neighborhoods, because people generally move to a nearby village to maintain their existing lifestyle.

The specific balancing causal loop of the distance effect works as follows. The increase in resident population leads to a lower vacancy rate (or a higher occupation rate), which results in the investment in new RVs to accommodate more potential residents. However, due to the lack of land supply in a fully-developed community, developers usually have to build new RVs in rural areas a long distance away from the original location, which reduce the attraction to potential residents (i.e. reducing the conversion rate), and thus reduce the number of new residents.

\section{Discussion}

In the CLD, the word-of-mouth and distance effects are the most dominant causal loops influencing the system behavior of the RV industry, with both clearly reflecting the social need of potential residents, especially baby boomers in their post-retirement life.

According to Stimson and McCrea (2004), the traditional advertising marketing strategy influences the choice of only one in ten residents, with majority having relocated due to their positive experience of visiting villages, or having friends, neighbors or family living there. It has been widely accepted that residents prefer to live in a socially-connected environment where they can make contact with their friends (both within and outside the village), original and new neighbors and family members (Buys, 2001; Buys et al., 2006). The word-of-mouth effect reflects the residents' need for a socially-connected environment that helps maintain their existing social networks and prevent consequential social isolation and loneliness. In addition, the word-of-mouth effect aligns with the Active Ageing concept developed by World Health Organization [WHO] $(2002,2007)$, which directly addresses the goal of maximizing older people's opportunities for ongoing participation with the wider society in order to enhance quality of life as people age. As active ageing traditionally involves maintaining community participation and engagement, social connections and a quality lifestyle through access to community environment, potential residents who have friends, neighbors or family living in the village or have previously visited the village are the most likely to move into the village to maintain their existing lifestyle and familiarity (Stimson \& McCrea, 2004).

By contrast, the distance of RVs from original communities plays an essential balancing effect to potential residents' relocation move. It has been well established that most older Australians wish to age-in-place, i.e., remain in their own home in the current community as long as possible (Australian Institute of Health and Welfare [AIHW], 2013). However, for many older people, leaving their community and moving into RVs serves as a more desirable option due to various reasons, such as reduced physical capabilities, increased risk of social isolation and the agetailored community environment of RVs (Rivera-Hernandez et al., 2015; Hu et al., 2020). Nevertheless, most potential residents choose a RV close to their original community due to their familiarity with existing living environment. The longer distance from their previous home is the most important variable preventing the relocation of potential residents (Stimson \& McCrea, 2004). For some people, leaving their community and friends to move into a RV is sometimes the beginning of a downswing in health because of the mental toll involved. 
Therefore, the word-of-mouth and location effects challenge the traditional ageing framework of "disengagement theory of ageing", with the underpinning assumption that withdrawing from society and living in age-segregated (normally gated) communities is natural and acceptable (Ebersole et al., 2005). RVs are not supposed to be places where older people are herded together, normally in a rural area, to simply pass time (Hoonaard, 2002). Instead, these communities need to challenge the negative perspectives of ageing, while positively influencing the health and wellbeing of those living there through the provision of a supportive social and built environment for active ageing (Graham \& Tuffin, 2004). Therefore, the RV industry should fully understand the housing and location choices of retiring Australians in the "baby boomer" generation (Pinnegar et al., 2012, p. 34), and explore the "suitability of particular aged housing or retiring housing options" within a rapidly changing community by re-positioning itself to provide inclusive community accommodation and facilitate active ageing or ongoing participation for retirees.

The price or affordability balancing effect (B2) and the new supply reinforcing effect (R2) reflect the demandand-supply mechanism of the retirement village industry. When more residents live in retirement villages, it will drive up the price and reduce the conversion rate of potential residents consequently especially when the vacancy rate is low. However, this effect will last long as the industry will build new retirement villages to cater to the accommodation needs of potential residents. Nevertheless, as the built or supply of new retirement villages takes time because of the construction period and the marketing and sale time needed, the delay of supply and price fluctuation will usually occur.

\section{Conclusions}

The future growth of the RV industry largely depends on whether this accommodation option can provide an age-friendly environment to meet the unique living requirements of older people. The dynamics underlying the decision-making of potential residents is a complex process that involves multiple interactive factors evolving over time. The present study proposes a CLD, a widely used approach for system thinking, to reveal the inter-relationships between these factors and capture how the dynamics of such relationships change over time. It is found that the word-of-mouth effect and new supply of RVs are the major reinforcing loops that result in the continuous growth of the resident population. Meanwhile, the moveout effect, affordability effect and distance to original communities are the major balancing loops that help reduce growth and bring system stability. Of these causal loops, the word-of-mouth effect reveals the primary reason why potential residents move into retirement villages, while the far distance to the original community/home is regarded as the major concern of potential residents that adversely affect their relocation decision making. Therefore, these two causal loops are the primary drivers of the system be- haviour and reflect the social requirements of potential residents, i.e. to keep social connection and engagement with original local communities.

Although the CLD, at this stage, lacks quantitative relationships between variables and not all the variables are included, it is the most frequently employed tool for model conceptualisation. The CLD is the first step to help predicting the future growth of the RV industry (e.g. the population of residents, the number of RVs and the capacity limit of the industry) in following decades. It will also pave the way for following the steps of model development, model simulation and policy analysis. The quantitative modelling in the next stage research will be conducted to estimate the parameters in a comprehensive and updated causal loop diagram and stock and follow diagram, run simulation of the parameters to get the similar behaviour of the reference model, conduct sensitivity analysis, and finally test the impact of policies/ variables on the future growth of the industry.

In addition, the CLD already reveals the underlying mechanisms that drive industry growth and, more importantly, identifies the most influential causes of industry behaviour. Thus, it can still provide some practical implications for the industry. For example, give the importance of the home-retirement village distance to residents, developers are suggested to consider providing new accommodations in existing retirement villages (e.g. turning the low set village to high-rises apartments) as their priority to attract potential residents rather than build new ones in remote areas. Similarly, encouraging current residents to reach out and contact more potential residents would be probably a more effective marketing strategy than investing on traditional advertisements channels (e.g. newspapers, magazines and television programs). Finally, as the population ageing is a global phenomenon and the retirement village living is widely accepted in developed countries, the CLD developed in Australia can act as a useful reference for these countries to further reveal their future industry growth and develop relevant policies to improve the quality of life of RV residents.

\section{Funding}

This work was supported by the Australian Research Council (ARC) under Grant [number DP170101208] and Papua New Guinea University of Technology.

\section{Author contributions}

Bo Xia and Qing Chen were responsible for the design and development of the data analysis and draft of the article. Jerry Walliah was responsible for data collection. Laurie Buys, Martin Skitmore and Connie Susilawati were responsible for data interpretation.

\section{Disclosure statement}

The authors have no competing financial, professional, or personal interests from other parties. 


\section{References}

Adams, K. B., Sanders, S., \& Auth, E. A. (2004). Loneliness and depression in independent living retirement communities: risk and resilience factors. Aging \& Mental Health, 8(6), 475485. https://doi.org/10.1080/13607860410001725054

Agnew, S., Smith, C., \& Dargusch, P. (2018). Causal loop modelling of residential solar and battery adoption dynamics: a case study of Queensland, Australia. Journal of Cleaner Production, 172, 2363-2373.

https://doi.org/10.1016/j.jclepro.2017.11.174

Albin, S., Forrester, J. W., \& Breierova, L. (2001). Building a system dynamics model: Part 1: conceptualization. MIT.

Arnold, R. D., \& Wade, J. P. (2015). A definition of systems thinking: a systems approach. Procedia Computer Science, 44, 669-678. https://doi.org/10.1016/j.procs.2015.03.050

Australian Bureau of Statistics. (2012). Reflecting a nation: stories from the 2011 census, 2012-2103. https://www.abs.gov.au/ ausstats/abs@.nsf/lookup/2071.0main+features902012-2013

Australian Institute of Health and Welfare. (2013). The desire to age in place among older Australians. https://www.aihw.gov. $\mathrm{au} /$ reports/older-people/the-desire-to-age-in-place-amongolder-australians/contents/table-of-contents

Bernard, M., Bartlam, B., Sim, J., \& Biggs, S. (2007). Housing and care for older people: life in an English purpose-built retirement village. Aging \& Society, 27(4), 555-578. https://doi.org/10.1017/S0144686X07005983

Bohle, P., Rawlings-Way, O., Finn, J., Ang, J., \& Kennedy, D. J. (2014). Housing choice in retirement: community versus separation. Housing Studies, 29, 108-127.

https://doi.org/10.1080/02673037.2013.825693

Buys, L., Miller, E., \& Barnett, K. (2006). The personal, practical and policy implications of older Australians' residential choice. Journal of Housing for the Elderly, 20, 31-46. https://doi.org/10.1300/J081v20n01_03

Buys, L. R. (2001). Life in a retirement village: implications for contact with community and village friends. Gerontology, 47, 55-59. https://doi.org/10.1159/000052771

Buys, L., \& Miller, E. (2007). The physical, leisure and social activities of very old Australian men living in a retirement village and the community. Geriaction, 25(2), 15.

Charmaz, K. C. (2006). Constructing grounded theory: a practical guide through qualitative analysis. Sage.

Cotter, N., Monahan, E., McAvoy, H., \& Goodman, P. (2012). Coping with the cold-exploring relationships between cold housing, health and social wellbeing in a sample of older people in Ireland. Quality in Ageing and Older Adults, 13(1), 38-47. https://doi.org/10.1108/14717791211213607

Crisp, D. A., Windsor, T. D., Anstey, K. J., \& Butterworth, P. (2013). What are older adults seeking? Factors encouraging or discouraging retirement village living. Australasian Journal on Ageing, 32(3), 163-170.

https://doi.org/10.1111/j.1741-6612.2012.00623.x

Ebersole, P., Hess, P., \& Touhy, T. (2005). Gerontological nursing \& healthy aging. Mosby.

Faulkner, D. (2007). The older population and changing housing careers: implications for housing provision. Australasian Journal on Ageing, 26(4), 152-156. https://doi.org/10.1111/j.1741-6612.2007.00245.x

Forrest, J. (2008). A response to paper "Systems Thinking" by D. Cabrera et al.: additional thoughts on systems thinking. Evaluation and Program Planning, 31, 333-334. https://doi.org/10.1016/j.evalprogplan.2008.04.008
Gardner, I. L., Browning, C., \& Kendig, H. (2005). Accommodation options in later life: retirement village or community living? Australasian Journal on Ageing, 24(4), 188-195. https://doi.org/10.1111/j.1741-6612.2005.00121.x

Gracia, N., Moyle, W., Oxlade, D., \& Radford, K. (2010). Addressing loneliness in a retirement village community: a pilot test of a print-delivered intervention. Australasian Journal on Ageing, 29, 179-182.

https://doi.org/10.1111/j.1741-6612.2010.00442.x

Graham, V., \& Tuffin, K. (2004). Retirement villages: companionship, privacy and security. Australasian Journal on Ageing, 23(4), 184-188.

https://doi.org/10.1111/j.1741-6612.2004.00047.x

Grant, B. C. (2007). Retirement villages: more than enclaves for the aged. Activities, Adaptation \& Aging, 31(2), 37-55.

https://doi.org/10.1300/J016v31n02_03

Hoonaard, D. (2002). Life on the margins of a Florida retirement community: the experience of snowbirds, newcomers and widowed persons. Research on Ageing, 24(1), 50-66.

https://doi.org/10.1177/0164027503024001004

Hu, X., Xia, X., Skitmore, M., Buys L., \& Zuo J. (2017). Retirement villages in Australia: a literature review. Pacific Rim Property Research Journal, 23(1), 101-122.

https://doi.org/10.1080/14445921.2017.1298949

Hu, X., Xia, B., Chong, H.-Y., Skitmore, M., \& Buys, L. (2020). Improving the sustainable retirement village framework: from theory to practice. Journal of Cleaner Production, 248, 119290. https://doi.org/10.1016/j.jclepro.2019.119290

Kim, H., \& Andersen, D. F. (2012). Building confidence in causal maps generated from purposive text data: mapping transcripts of the Federal Reserve. System Dynamics Review, 28, 311-328. https://doi.org/10.1002/sdr.1480

Kwoun, M.-J., Lee, S.-H., Kim, J.-H., \& Kim, J.-J. (2013). Dynamic cycles of unsold new housing stocks, investment in housing, and housing supply-demand. Mathematical and Computer Modelling, 57(9-10), 2094-2105. https://doi.org/10.1016/j.mcm.2011.08.005

Nathan, A., Wood, L., \& Giles-Corti, B. (2014). Perceptions of the built environment and associations with walking among retirement village residents. Environment and Behavior, 46(1), 46-69. https://doi.org/10.1177/0013916512450173

Omoto, A. M., \& Aldrich, C. D. (2006). Retirement community life: issues, challenges, and opportunities. Annual Review of Gerontology and Geriatrics, 26, 283-303.

Parliament of Australia. (2007). Older people and the law. House Standing Committee Legal and Constitutional Affairs.

Pinnegar, S., van den Nouwelant, R., Judd, B., \& Randolph, B. (2012). Understanding housing and location choices of retiring Australians in the 'baby boom' generation (Scoping Report prepared for the National Housing Supply Council). City Futures Research Centre.

Property Council of Australia. (2014). National overview of the retirement village sector. https://www.grantthornton.com.au/insights/ reports/national-overview-of-the-retirement-village-sector/

PwC. (2019). PwC/Property council retirement census. https:// retirement.propertycouncil.com.au/retirement-census

Rivera-Hernandez, M., Yamashita, T., \& Kinney, J. M. (2015). Identifying naturally occurring retirement communities: a spatial analysis. The Journals of Gerontology: Series B, 70(4), 619-627. https://doi.org/10.1093/geronb/gbu077

Seifert, A., \& Schelling, H. R. (2018). Attitudes toward aging and retirement homes before and after entry into a retirement home. Journal of Housing for the Elderly, 32(1), 12-25. https://doi.org/10.1080/02763893.2017.1393484 
Sim, J., Bartlam, B., \& Bernard, M. (2011). The CASP-19 as a measure of quality of life in old age: evaluation of its use in a retirement community. Quality of Life Research, 20(7), 9971004. https://doi.org/10.1007/s11136-010-9835-x

Sterman, J. D. (2001). Business dynamics: system thinking and modeling for a complex world. Irwin McGraw-Hill.

Stimson, R. J., \& McCrea, R. (2004). A push - pull framework for modelling the relocation of retirees to a retirement village: the Australian experience. Environment and Planning A, 36(8), 1451-1470. https://doi.org/10.1068/a36206

Walker, E., \& McNamara, B. (2013). Relocating to retirement living: an occupational perspective on successful transitions. Australian Occupational Therapy Journal, 60, 445-453. https://doi.org/10.1111/1440-1630.12038

World Health Organization. (2002). Active ageing: a policy framework. https://apps.who.int/iris/handle/10665/67215

World Health Organization. (2007). Global age-friendly cities: a guide. https://www.who.int/ageing/publications/Global_age_ friendly_cities_Guide_English.pdf
Wright, D., Buys, L., Vine, D., Xia, B., Skitmore, M., Drogemuller, R., Kennedy, R., \& Lei, M. (2014). EUTOPIA 75+: exploratory futures scenarios for baby boomers' preferred living spaces. Journal of Futures Studies, 19(2), 41-60.

Xia, B., Zuo, J., Skitmore, M., Buys, L., \& Hu, X. (2014). Sustainability literacy of older people in retirement villages. Journal of Aging Research, 2014, 919054. https://doi.org/10.1155/2014/919054

Xia, B., Zuo, J., Skitmore, M., Chen, Q., \& Rarasati, A. D. (2015). Sustainable retirement village for older people: a case study in Brisbane, Australia. International Journal of Strategic Property Management, 19, 149-158. https://doi.org/10.3846/1648715X.2015.1029564

Yearworth, M., \& White, L. (2013). The uses of qualitative data in multi-methodology: developing causal loop diagrams during the coding process. European Journal of Operational Research, 231, 151-161. https://doi.org/10.1016/j.ejor.2013.05.002

Zuo, J., Xia, B., Barker, J., \& Skitmore, M. (2014). Green buildings for greying people: a case study of a retirement village in Australia. Facilities, 32, 365-381. https://doi.org/10.1108/F-08-2011-0060 